\title{
Building Social Science Simulations for College Students Using VR Headsets
}

\author{
Brendan G. Beal \\ University of Montevallo, Montevallo, USA \\ Email: bbeal@montevallo.edu
}

How to cite this paper: Beal, B. G. (2021). Building Social Science Simulations for College Students Using VR Headsets. Open Journal of Social Sciences, 9, 61-69. https://doi.org/10.4236/jss.2021.98006

Received: June 9, 2021

Accepted: August 1, 2021

Published: August 4, 2021

Copyright $\odot 2021$ by author(s) and Scientific Research Publishing Inc. This work is licensed under the Creative Commons Attribution International License (CC BY 4.0).

http://creativecommons.org/licenses/by/4.0/ (c) (i) Open Access

\begin{abstract}
This article outlines the original design and implementation of a virtual reality simulation for use in a college practice class. The simulation functions as a training opportunity and quick assessment of group leadership skills. VR headset makers like HTC, Oculus, or smart phone set-ups provide high-fidelity, immersive experiences, and this simulation was designed from the ground up to provide a unique set of situations for a specific class. In combination with the VR component, an immediate debrief with students afterwards connects the process in order to link theory and practice. The simulation was prototyped and built in five phases. This article covers lessons learned from each of the five phases: starting costs and equipment, partnerships, basic concept design, freelance developer hiring, and recommendations for course implementation.
\end{abstract}

\section{Keywords}

Simulated Client, Virtual Reality Headset, Empathy Machine, Role Play, Gamification, HMD

\section{Introduction}

Using simulation within college courses has occurred for years. Examples include role plays (Vapalahti, Marttunen, \& Laurinen, 2013), gamification of lessons, and any educational experience that attempts to mirror a real-world situation for students. As Bogo, Rawlings, Katz, and Logie (2014) put it in their book on simulation, these types of experiences, if designed carefully, can provide students "excellent training opportunities for developing holistic competence" (p. 100). Further examples of academic simulations include video recordings that aid in teaching practice skills (Asakura, Bogo, Good, \& Power, 2018), using the virtual world Second Life to simulate client contact with social work interns (Wil- 
son, Brown, Wood, \& Farkas, 2013), and more increasingly simulating virtual clinical experiences (Anstadt, Bradley, Burnette, \& Medley, 2013; Levine \& Adams, 2013; Williams-Gray, 2014; Washburn \& Zhou, 2018). With the world of traditional education challenged to provide more online or distance services, and with the increasing likelihood of more distance education in the future; the next logical step in simulation for students is using a virtual reality (VR) headset to experience situations applicable to their interests.

Modern day VR devices are worn over the eyes and encompass the entire field of vision. Along with headphones or earbuds, this experience is extremely immersive and can deeply engage a student within a simulated scenario. These scenarios can range from a virtual field trip, or a more involved simulation where the student has agency and the environment reacts. VR headsets can be used to immerse a student into a social environment and practice skills safely and repeatedly. Only recently has this technology become affordable and widely available. Course instructors can build simulations that provide students with concrete leadership experience, allow them to demonstrate a basic understanding of action skills, test or provoke students in a safe environment, provide a critical practice event without actual client risk, and allow the study of complex social skills repeatedly.

As outlined by Bogo et al. (2014), debriefing the students afterwards with regard to what happened in the simulation gives an opportunity to analyze their virtual decisions and reflect on the linkage of theory to practice. An example of a VR headset simulation with debrief afterwards can look like a student putting on a headset, looking around the scenario and listening to characters, interacting and making choices, watching and listening to the characters react, and then coming out of the headset to interpret the meaning behind these actions with an instructor or partner.

This article describes the full development of a VR group leadership simulator, designed for undergraduate students in a social science class. It is written to show the process and potential of building a VR simulation from the ground up with very little computer programming knowledge. This process was undertaken by a social science faculty member at a small college, and presented as a guide to VR development.

\section{Literature Review}

Without as many constraints as compared to a traditional, two-dimensional game or video, VR can bring significant advantages by allowing exposure to numerous situations with the creation of a strong feeling of presence (Klinger et al., 2005). This is a different form of immersive experience that is usually not felt as much in other media. This type of VR experience has been shown to have value in evacuation trainings (Feng et al., 2018), providing a low stress way to improve speaking skills (North, North, \& Coble, 2017), or in the field of health and wellness. 
In a systematic review of randomized control trials that used VR in a medical setting (Dascal et al., 2017), it was found that VR could be generally efficacious with patients, and that VR was a "promising intervention with several potential applications in the inpatient medical setting" (p. 14). In a review of applied simulations for mental healthcare, VR was generally found to be valuable in anxiety-related interventions (ex. provoking reactions to stimuli) and pain management, but that more studies were needed in this area (Jerdan et al., 2018).

The most applicable research pertaining to the VR simulation related for this manuscript project deals with education studies. A review of HMD (headmounted display) use in education and training found that while more quality studies need to take place, a number of situations exist where HMDs are useful (Jensen \& Konradsen, 2017). These situations include understanding spatial information, practicing visual scanning skills, and controlling or testing emotional responses. Another study (Martin-Gutierrez et al., 2017) found that VR use within the educational sector will be one of the best uses of this technology because students are free to explore and interact in VR and "can investigate, experiment, and obtain feedback, resulting in an experience that improves their learning" (p. 479). However, at least one study has found that adding virtual learning simulations to university students' science labs caused more presence, but less actual learning (Makransky, Terkildsen, \& Mayer, 2019). More highquality research on this subject is needed.

\section{Purpose and Objective}

This article outlines the steps of creating a virtual reality software program, as demonstrated by a small liberal arts university department. The actual VR program developed was a five minute digital role-play called "Social Work with Groups VR". It allows students to practice calling on group members at a meeting within a VR headset. The purpose of this article is to show the pitfalls of creating educational content like this, show the reasoning behind building rather than buying off the shelf, and examine the instructor experiences. The sections of this article include equipment, pedagogical idea development, basic software, partnerships and contractors, and testing and implementation.

\subsection{Equipment Needed to Start Building a VR Simulation}

VR simulations made for a headset are first started with a design software program. Having both a computer that is VR-ready (i.e. great graphics card and processor), and having the type of headset you are ultimately making this for, is a necessity. The initial starting costs of building high-fidelity VR can vary. A staff member or instructor attempting to build custom VR simulations from the ground up can end up spending $\$ 3000$ - $\$ 4000$. This is assuming very little programming expertise on the part of the builder and no starting equipment. If the person designing a VR simulation has any experience such as several computer science classes, or the use of a computer lab somewhere, the costs are reduced significantly. VR headsets using smart phones are also much cheaper. 
Table 1. Minimum equipment, software, and contractor costs for "social work with groups".

\begin{tabular}{ccc}
\hline Hardware/Software & Cost $(\$)$ & Brand \\
\hline High fidelity VR headset & $\$ 600$ & HTC Vive \\
Gaming computer & $\$ 2200$ & Alienware laptop \\
Contractor: Freelance programmer time & $\$ 1000$ & VR developer hired through Upwork.com \\
(30 hours) & $\$ 3800$ & \\
TOTAL & & \\
\hline
\end{tabular}

The hardware and software suggested to build VR include a computer and VR headset, which are the bulk of all costs. It is important to decide between a laptop or desktop and decide between the more expensive VR head-mounted displays (ex. HTC Vive, Oculus Rift, or HoloLens) or the less expensive, standalone (i.e. no computer needed to experience it on the participant end) VR headsets (ex. Oculus Quest, Samsung Gear VR, or Google Cardboard). Audio recording equipment (ex. microphone, phone, or laptop) is also suggested. A software program for building games is required. The free game design program Unity $3 \mathrm{D}$ is suggested because there is no coding required within Unity $3 \mathrm{D}$, and it has a "what-you-see-is-what-you-get" user interface.

The VR simulator this article is based on is called "Social Work with Groups". The equipment used and other costs for this project are listed in Table 1.

Not listed in Table 1 is the cost of a microphone for recording dialogue, some digital assets that are often free to download, and the extra peripherals purchased with the HTC Vive that were not needed. Also not listed in Table 1 is the cost of a motion capture suit used to animate avatars. During the building of "Social Work with Groups VR", a $\$ 1400$ suit made by Perception Neuron was used to capture the movements of avatars for use within the simulation. This was an experimental idea that, in hindsight, was too expensive. Digital assets like avatars are easy to find online and animations are also available. While it was interesting to customize the movement of the simulated characters, it was not needed.

\subsection{Pedagogical Idea Development of the Simulation}

After getting the startup equipment, the next step in the build is to figure out the concept of what is being simulated. This is the core idea and involves deciding what students should learn and experience from the exercise. For social science simulations, this might include avatars that will speak and act like real people. Examples of scenarios are home visits, client assessments, or therapeutic interventions. It is imperative to first write a comprehensive design document that details the description, objectives, and flow of experiences. This is telling a short story in VR. This part of the project is a mix between script writing, game logic design, and research on realistic human behaviors as outlined by the literature. The reasoning behind creating an entire back-story is related to what Jensen and Konradsen (2017) discuss in their assertion that VR simulations on the current 


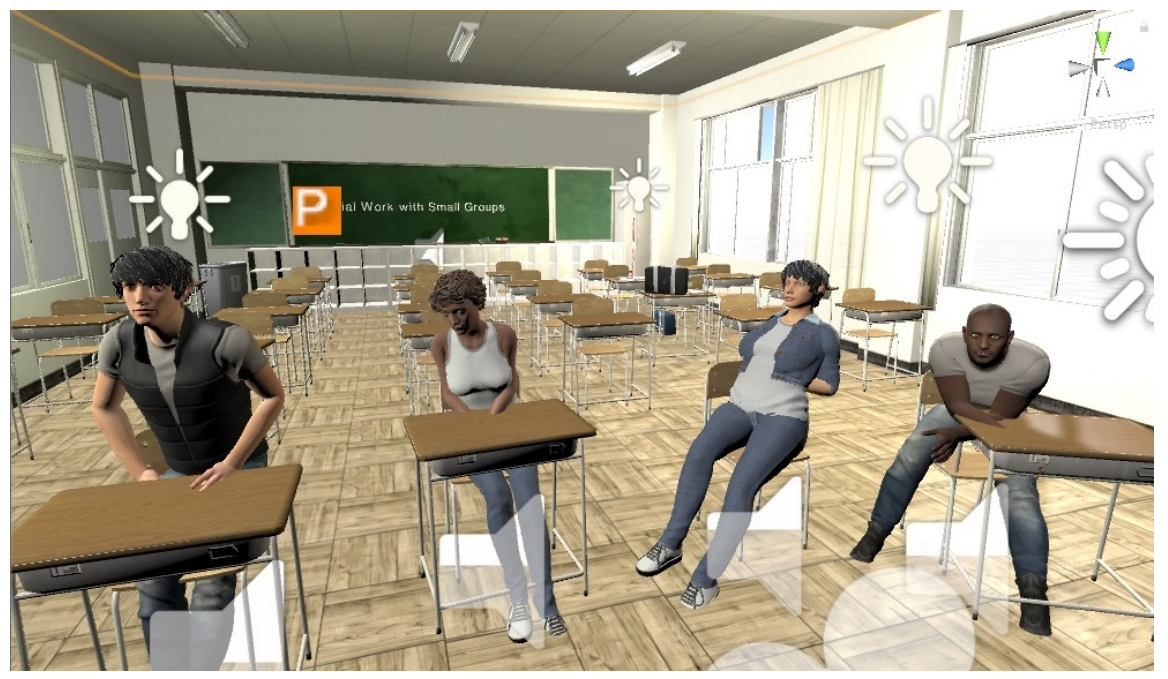

Figure 1. Screen capture from "Social Work with Groups VR".

market were "not designed as a tool to be used at different educational levels and with different pedagogical approaches" (p. 11).

The design document can include an outline or script of avatar behavior and dialogue. This is similar to the structure of a "Choose-Your-Own-Adventure" story. The design document outlines the pre-instruction, what happens from the moment the participant starts the simulation, and finally when they take off their headset. This can involve branching narratives (i.e. participant calls on a member of the virtual group and a certain line of dialogue plays for that specific order of actions) and can include game logic (Figure 1).

The setting and game logic for "Social Work with Groups VR" is a classroom with four clients sitting in front of the participant. The game structure rewards the player for actively listening to this treatment group and choosing which client to call on in order to facilitate appropriate self-disclosures. Dialogue progresses using audio files recorded by students from the university theater department. A simple scoring system was put in place so participants would be graded at the end by a narrator's voice. This grade is intended to reveal whether or not the player listened and acted professionally during the session. Most of the theoretical background for these design elements came from the textbook associated with the school's "Social Work with Groups" course (Toseland \& Rivas, 2017).

The experience of writing the design document and coming up with the idea for the simulation was interesting for the instructor. It took many hours to figure out an appropriate story, give actionable choices, and operationalize leadership behaviors so that players are asked to question their own skill. This step in the process involves being creative and knowledgeable of the diverse stories that clients can tell.

\subsection{Basic Software}

Downloading a game engine like Unity $3 \mathrm{D}$ to your VR-enabled computer is ne- 
cessary. This free game design software sets the stage and runs the program for the VR headset. Isar (2018) reported that it was the most suitable game engine for VR. With a very basic knowledge gained through online video tutorials one can start a blank scene and begin editing a basic virtual environment. More complicated programming is required for the avatars to be more interactive or for features like clickable buttons. However, uploading simple indoor or outdoor settings, customizable avatars, and audio are possible for a novice.

There are many kinds of software to build in VR. Learning one system is complicated enough so it might be recommended to pick one that works for your team and commit to it. When "Social Work with Groups VR" was started in Unity, it was approached simply and started with adding free avatar models, a few other assets found online, and ultimately passing it on to an experienced programmer. Unless someone on the team has advanced coding knowledge with games, the final bit of game logic programming will probably come from a hired contractor. Outlining and setting up as much of the simulation as possible on the front end will ensure the success of this next step.

\subsection{Partnerships and Contractors}

It is imperative to partner with others such as faculty, teachers, computer science majors, researchers, education specialists, or any individual or community trying to harness technology for social good. "Social Work with Groups VR" took approximately 80 hours to create so the more people sharing in the process, the easier. These partnerships included the Social Work program, the Game Studies and Design minor, theater majors answering an ad for free voice-over work, the university library, and Upwork.com. Funding came from a variety of these sources, as well as a research grant from the college.

\subsection{Hiring a Programmer}

The last step to finishing the simulation is finding someone who knows enough about programming to put together the final executable file. While finding a gig economy worker can be daunting, it is the easiest way to get affordable programming when one doesn't have a senior computer science major willing to help. It is important to have the exact specs of the simulation mapped out in the design document. The pay for the work must also be a fair amount. While simple projects might only require $\$ 1000$, it could easily cost $\$ 4000$ if a freelancer at the top of his or her game is required and/or located in a certain time zone.

The process of posting a project to a website, interviewing over email, video chatting about ideas, and finally receiving the finished product can take a couple of weeks if people are motivated, or a few months if not. This timeline depends on the original design document, who is partnered or hired, and unexpected changes along the way. Negotiating to have a final tested product before the last payment for services is a good idea.

These steps for sending your somewhat-formed VR experience to a program- 
mer should take place regardless of if you hire in-house or online. The project "Social Work with Groups VR" hired an online software freelancer through Upwork.com. The project took longer than expected at this stage in development because multiple programmer interviews fell through. If the project were to be done again, the instructor would first try to exhaust the local network of talent. This may include student organizations, non-profits, or technology companies.

\subsection{Testing and Implementation of the VR Simulation in Class}

Bringing VR to class can be a fun but time-consuming event. The amount of time spent can depend on the amount and type of headsets available, and space available. The headset can be cleaned and sanitized easily, although multiple face cushions are recommended. Sharing a unique VR experience with a room full of people can be similar to sitting through many short presentations that are all on the same topic. If there are several devices like the smaller, untethered Oculus Quest, several students can experience the simulation at the same time and little time is needed to complete the activity. If a more cumbersome early generation headset is used, the simulation may run for over an hour if ten students are lined up.

Simulations within an educational course should be completed and then discussed afterwards in individual or group debriefs. "Social Work with Groups VR" followed a protocol in which students first completed the simulation with an assistant's help, then immediately sat down with an instructor afterwards to debrief. This individual debrief afterward included questions about the student's score, why they thought they received that score, what they could have done differently, and comments on how they would react if they were in this situation in the field. A more in-depth, formative assessment is recommended if more qualitative or quantitative data are needed from students (Bogo et al., 2014); but a simple debrief can help students think critically about their actions.

"Social Work with Groups VR" went through a piloting process that tested it on a single class. The experiences related to implementing the VR project in class were mostly positive. Although not everyone could participate, the majority of those that did reported that the activity could help them learn practice skills. The process involved signing up for time slots to participate and also getting a volunteer to help assist with taking the headset on and off. The one-on-one debriefs with the students directly afterwards were most important. During these, students reviewed client assessment strategies, previous communication decisions, and dealing with hypothetical confidentiality breaches. Overall, very positive results were found.

There are certainly limitations for making these simulators on a limited budget, however. "Social Work with Groups VR" had issues related to the avatars clipping and moving in unrealistic ways. It also had to take small shortcuts with the programming as well (e.g. the end score doesn't tabulate exactly as intended). Regardless, this technology is so novel that even simplified versions can 
make a big impression on participants as well as help students connect theory and practice skills.

\section{Conclusion}

The prevalence of distance or remote learning in the future is unknown, but it is safe to say that there is great focus on it at the moment. VR headset experiences are a possible solution to making educational simulations more immersive. Future projects would spend less money than the example simulation and use the majority of the budget to pay a programmer to develop a more immersive lesson. Future studies in this area can use more experimental research design and also work with adjacent technologies like 360 video or augmented reality (AR).

\section{Conflicts of Interest}

The author declares no conflicts of interest regarding the publication of this paper.

\section{References}

Anstadt, S. P., Bradley, S., Burnette, A., \& Medley, L. L. (2013). Virtual Worlds: Relationship between Real Life and Experience in Second Life. International Review of Research in Open \& Distance Learning, 14, 160-190. https://doi.org/10.19173/irrodl.v14i4.1454

Asakura, K., Bogo, M., Good, B., \& Power, R. (2018). Teaching Note-Social Work Serial: Using Video-Recorded Simulated Client Sessions to Teach Social Work Practice. Journal of Social Work Education, 54, 397-404. https://doi.org/10.1080/10437797.2017.1404525

Bogo, M., Rawlings, M., Katz, E., \& Logie, C. (2014). Using Simulation in Assessment and Teaching: OSCE Adapted for Social Work. Council on Social Work Education.

Dascal, J., Reid, M., Ishak, W. W., Spiegel, B., Recacho, J., Rosen, B., \& Danovitch, I. (2017). Virtual Reality and Medical Inpatients: A Systematic Review of Randomized, Controlled Trials. Innovative Clinical Neuroscience, 14, 14-21.

Feng, Z., Gonzalez, V., Amor, R., Lovreglio, R., \& Cabrera-Guerrero, G. (2018). Immersive Virtual Reality Serious Games for Evacuation Training and Research: A Systematic Literature Review. Computers \& Education, 127, 252-266. https://doi.org/10.1016/j.compedu.2018.09.002

Isar, C. (2018). A Glance into Virtual Reality Development Using Unity. Informatica Economica, 22, 14-22. https://doi.org/10.12948/issn14531305/22.3.2018.02

Jensen, L., \& Konradsen, F. (2017). A Review of the Use of Virtual Reality Head-Mounted Displays in Education and Training. Educational Informational Technology, 23, 15151529. https://doi.org/10.1007/s10639-017-9676-0

Jerdan, S. W., Grindle, M., van Woerden, H. C., \& Kamel-Boulos, M. N. (2018). Head Mounted Virtual Reality and Mental Health: Critical Review of Current Research. JMIR Serious Games, 6, Article No. e14. https://doi.org/10.2196/games.9226

Klinger, E., Bouchard, S., Légeron, P., Roy, S., Lauer, F., Chemin, I., \& Nugues, P. (2005). Virtual Reality Therapy versus Cognitive Behavior Therapy for Social Phobia: A Preliminary Controlled Study. CyberPsychology \& Behavior, 8, 76-88. https://doi.org/10.1089/cpb.2005.8.76

Levine, J., \& Adams, R. H. (2013). Introducing Case Management to Students in a Virtual 
World: An Exploratory Study. Journal of Teaching in Social Work, 33, 552-565. https://doi.org/10.1080/08841233.2013.835766

Makransky, G., Terkildsen, T. S., \& Mayer, R. E. (2019). Adding Immersive Virtual Reality to a Science Lab Simulation Causes More Presence but Less Learning. Learning and Instruction, 60, 225-236. https://doi.org/10.1016/j.learninstruc.2017.12.007

Martin-Gutierrez, J., Mora, C. E., Anorbe-Díaz, B., \& Gonzalez-Marrero, A. (2017). Virtual Technologies Trends in Education. EURASIA Journal of Mathematics, Science \& Technology Education, 13, 469-486. https://doi.org/10.12973/eurasia.2017.00626a

North, M. M., North, S. M., \& Coble, J. R. (2017). Virtual Reality Therapy: An Effective Treatment for the Fear of Public Speaking. International Journal of Virtual Reality (IJVR), 3, 1-6. https://doi.org/10.20870/IJVR.1998.3.3.2625

Toseland, R. W., \& Rivas, R. F. (2017). An Introduction to Group Work Practice. Pearson Allyn \& Bacon.

Vapalahti, K., Marttunen, M., \& Laurinen, L. (2013). Online and Face-to-Face Role-Play Simulations in Promoting Social Work Students' Argumentative Problem Solving. Journal of Comparative Social Work, 8, 6-40. https://doi.org/10.31265/jcsw.v8i1.92

Washburn, M., \& Zhou, S. (2018). Teaching Note-Technology-Enhanced Clinical Simulations: Tools for Practicing Clinical Skills in Online Social Work Programs. Journal of Social Work Education, 54, 554-560. https://doi.org/10.1080/10437797.2017.1404519

Williams-Gray, B. (2014). Preparation for Social Service Leadership: Field Work and Virtual Organizations That Promote Critical Thinking in Administration Practice. Journal of Teaching in Social Work, 34, 113-128. https://doi.org/10.1080/08841233.2014.892050

Wilson, A. B., Brown, S., Wood, Z. B., \& Farkas, K. J. (2013). Teaching Direct Practice Skills Using Web-Based Simulations: Home Visiting in the Virtual World. Journal of Teaching in Social Work, 33, 421-437. https://doi.org/10.1080/08841233.2013.833578 